\title{
Morbidity and Mortality Rounds in Liver Transplantation
}

\author{
Peri Kocabayoglua ${ }^{a}$ Martin Husen ${ }^{b}$ Oliver Witzke ${ }^{c} \quad$ Andreas Kribben $^{c} \quad$ Fuat H. Saner $^{a}$ \\ Ali Canbay ${ }^{\mathrm{d}}$ Guido Gerken $^{\mathrm{d}}$ Andreas Paul $^{\mathrm{a}}$ \\ a Department of General, Visceral and Transplantation Surgery, Faculty of Medicine, University Hospital Essen, \\ University of Duisburg-Essen, Essen, Germany; \\ ${ }^{b}$ Department of Orthopedic Surgery and Trauma Surgery, Faculty of Medicine, University Hospital Essen, \\ University of Duisburg-Essen, Essen, Germany; \\ ${ }^{c}$ Department of Nephrology, Faculty of Medicine, University Hospital Essen, University of Duisburg-Essen, Essen, Germany; \\ ${ }^{\mathrm{d}}$ Department of Gastroenterology and Hepatology, Faculty of Medicine, University Hospital Essen, \\ University of Duisburg-Essen, Essen, Germany
}

\section{Keywords}

Morbidity and mortality conference .

Liver transplantation - Healthcare quality improvement . Medical error - Patient safety

\section{Summary}

Background: Morbidity and mortality conferences (MMCs) provide powerful opportunities for learning, reflection, and improvement. The current literature gives examples of how MMCs can be designed; however, no systematic review of cases and no original data related to liver transplantation are available. Liver transplantation requires a multidisciplinary approach to case identification, presentation, and analysis. Framework structures that guide case investigation are needed to successfully follow up on outcome measures and provide the basis for quality assessment and transparency in transplant programs. Methods: All cases presented at our department's transplant-related MMCs in the years 2014 and 2015 were analyzed. Patient data were collected from our electronic database and meeting minutes. Cases were summarized according to type of transplantation. Liver-related transplant cases were analyzed for in-house deaths and time from death until presentation at an MMC. A literature review was performed, and our center's MMC design was compared with the literature available on conducting MMCs and improving patient safety and quality of care. Results: Within 2 years, 15 MMCs were held at our department. 38 cases were discussed of which 25 were liver transplant-related. Most cases were in-house postoperative deaths, mainly due to sepsis or primary non-function. We provide a summary of recommendations for conducting MMCs based on conferences held in our department combined with the literature. Conclusion: We present our experience with MMCs held over the past 24 months in consideration of guidelines on MMCs provided in the literature. As there is little conformity to known models for analyzing medical incidents, models for best practice in conduction MMCs are urgently needed.

(c) 2016 S. Karger GmbH, Freiburg

\section{Introduction}

The morbidity and mortality conference (MMC) is the most visible stage for the critical evaluation of adverse events and errors in academic medicine, and has therefore been referred to as the 'golden hour' of surgical education [1]. Over the last century, it has become the most critical aspect of quality assurance and education in surgery departments. First recommendations pertaining to MMCs were documented by Codman [2] as a study in hospital efficiency, recommending the documentation of patient history and outcome analysis, including a systematic review of adverse events and a categorization of causative errors. Through its guidelines published in 1983, the American Accreditation Council of Graduate Medical Education (ACGME) required departments with surgical training programs to institute weekly reviews of 'all current complications and deaths, including radiologic and pathologic correlation of surgical specimens and autopsies' [3]. Ever since MMCs

\section{KARGER}

() 2016 S. Karger GmbH, Freiburg

Fax +497614520714 
were held, the exact structure of these meetings in terms of the presentation, discussion, and conclusion of clinical cases has remained at each department's discretion. This has resulted in a wide variation in how MMCs are conducted across medical departments with little conformity to structured models for analyzing medical incidents. For MMCs to successfully address medical errors and adverse events, individuals involved in a patient's treatment will have to identify the event, determine the reason for it to have occurred, and implement actions to reduce the likelihood of a similar event taking place.

For an adverse event to occur, it requires a system of security sentinels to fail at each level, ultimately providing a permissive environment leading the medical staff to fail in preventing a harmful or fatal outcome. A report from the National Institute of Medicine in 1999 highlighted the need for 'a comprehensive approach to improving patient safety', the critical first step in improving quality of care [4]. Errors were described to occur at all stages of the care process, from diagnosis, to treatment, to preventive care. This report preceded a follow-up report, drawing attention to flaws within the work environment leading to adverse events, rather than individuals being directly at fault [5-7]. The focus of MMCs has ever since shifted from the presentation and discussion of rare or difficult cases to the analysis of flaws in the department's structure and workflow.

National requirements for improving and monitoring patient safety have become a major focus for hospitals and their administrators. Surgical outcome data have to be made public and are potentially open to scrutiny, enhancing the attention in the public eye and media.

The mere presentation of raw data on outcome, mortality, and adverse events, however, lacks the opportunity to assess and analyze safety structures within the department. MMCs are therefore the most important tool for reviewing clinical cases and simultaneously taking action to guarantee improvements in patient safety and quality of care.

Although numerous approaches to structuring and improving quality measures following MMCs have been published in the literature, recommendations for MMCs in transplantation surgery are lacking.

In this article, we review all cases presented during monthly transplantation MMCs at our institution within the years 2014 and 2015, put our MMC design in context with the current literature, and aim to give recommendations on a structured approach to MMCs in transplantation surgery.

\section{Methods}

This is a retrospective analysis of cases presented at our department's transplant-related MMCs in the years 2014 and 2015. Patient data were collected from our electronic database as well as meeting minutes. Cases were summarized according to type of transplantation. All liver-related transplant cases were analyzed for in-house deaths, as well as time from death until presentation at an MMC. Also, the most prevalent causes of death were grouped.

\section{Surgical Quality and Safety Outcomes in Correlation with MMCs}

The outcome of surgical procedures depends not only on the patient's pathophysiological risk factors and the skills of the surgeon, but also on the quality of care the patient receives throughout his/her in-patient and out-patient treatment. This involves direct and indirect caregivers, which in turn are all influenced by the environment in which they perform their tasks [8].

In 1988, Campbell [9] first published a comprehensive guide to conducting surgical MMCs, which included recommendations on structure, schedule, participants, data collection and presentation, and even confidentiality and medicolegal implications, as well as the relationship between MMCs and a full surgical audit. This guideline aimed at setting up MMCs in order to make them beneficial and well run. Little evidence exists today on the impact a certain structure or design of an MMC has on improving patient safety and quality of care. Cases presented at MMCs are generally selected by members of the surgical staff, and include deaths as well as adverse and serious adverse events. However, a cut-off as to when a serious event will be reported remains undefined, as does the structure and format of the conference itself which may vary widely between institutions. MMCs based on a traditional selection in a surgical department have been described to underreport both in-hospital and post-discharge complications and deaths as compared with data collected using the American College of SurgeonsNational Surgical Quality Improvement Program (ACS-NSQIP) [10]. About half of all deaths and 3 out of 4 complications are not reported in the MMCs when compared to selection through ACSNSQIP. An evaluation of steps to improve the quality of MMCs in general and their contribution to the educational process was recently performed [11]. After implementing changes to the existing structure, residents as well as faculty members were asked to evaluate the 'improved' MMC format of their respective institution, which included 6 changes such as presentation style, time of literature review, faculty discussion, encouraging residents' involvement in the discussion, moving the conference from the afternoon to the morning, as well as discussing as many cases as possible rather than presenting 1 case at length. The new structure was welcomed mostly by the surgical residents. When comparing the structure of MMCs in internal medicine and surgery, adverse events are less likely to be presented in internal medicine than in surgery, although internal medicine cases were presented 3 times longer than surgical cases [12]. Also, errors are less often attributed to a specific cause in internal medicine than they are in surgical MMCs.

An MMC provides an adequate platform in which surgical procedures, workflow arrangements, and outcome measures can be presented, discussed, and improved with every individual involved in the clinical case. It allows for the combination of a structured identification and analysis system together with the surgeon's or healthcare provider's case presentation and experience. An understanding of factors enhancing surgical errors and affect outcome is crucial. Studies have demonstrated that about $10 \%$ of patients admitted will suffer some kind of harm, which in half of the cases is 
Table 1. Elements that help design MMCs

\begin{tabular}{|c|c|c|}
\hline \multirow[t]{3}{*}{ Schedule } & $\begin{array}{l}\text { frequency of MMCs held } \\
\text { scheduled on a regular } \\
\text { basis as a fixed meeting }\end{array}$ & $\begin{array}{l}\text { weekly/bi-weekly/monthly } \\
\text { invitations to be sent to team }\end{array}$ \\
\hline & time of day & $\mathrm{AM} / \mathrm{PM}$ within contracted sessional time \\
\hline & appropriate length & $45 / 60 \mathrm{~min}$ \\
\hline \multirow[t]{17}{*}{ Participants } & all types of healthcare & physicians \\
\hline & providers & assistants \\
\hline & & nurses (operating room, ICU, ward, clinic) \\
\hline & & transplant coordinators \\
\hline & all disciplines of & surgery \\
\hline & healthcare providers & anesthesiology \\
\hline & & immunology \\
\hline & & infectious diseases \\
\hline & & hepatology \\
\hline & & pediatrics \\
\hline & & pathology \\
\hline & & radiology \\
\hline & chairmanship & head of department \\
\hline & & surgical consultant as moderator \\
\hline & & selection of cases \\
\hline & & guide discussion \\
\hline & & surgical consultants rotate \\
\hline \multirow[t]{7}{*}{ Data } & collection & collection assigned to a member of the team \\
\hline & presentation & $\begin{array}{l}\text { time between incident and presentation to be kept short } \\
\text { presentation by clinician most closely involved supported } \\
\text { by the entire team }\end{array}$ \\
\hline & content/cases & all deaths \\
\hline & & grade III complications [25] \\
\hline & & $\begin{array}{l}\text { all types of complications can be selected for potential dis- } \\
\text { cussion }\end{array}$ \\
\hline & & no restriction to a limited number of cases \\
\hline & & $\begin{array}{l}\text { statistical analysis of type and incidence of complications } \\
\text { at the end of each year }\end{array}$ \\
\hline \multirow[t]{3}{*}{ Outcome } & follow-up & $\begin{array}{l}\text { team decides on how to follow up on suggested improve- } \\
\text { ments }\end{array}$ \\
\hline & & distribution of recommendations to the entire team \\
\hline & review & statistical analysis on incidents presented annually \\
\hline
\end{tabular}

preventable $[13,14]$. The incidence of adverse events among hospitalized patients who undergo an operation is $3.0 \%$, again with half of the cases being preventable [13]. In the United Kingdom, an acceptable mortality rate lies within $5-10 \%$ for major operations with a complication rate of $20-25 \%$ [15]. Mortality decreases as the number of surgeries performed per center and individual surgeon increases $[16,17]$. Recently, medical error has been listed as the third leading cause of death in the USA [18]. Even though death certificates require an International Classification of Diseases (ICD) code to identify the cause of death, the number of deaths as a consequence of medical error itself will remain unmeasured and therefore be underestimated.

Liver transplant recipients represent a unique and complex entity of patients. With their underlying liver disease and multidisciplinary treatment requirements, a multidisciplinary approach to morbidity and mortality, which includes a wide range of medical disciplines, is essential. The proportion of liver transplant recipients with significant comorbidities has increased over the past decade [19]. Between 1999 and 2008, the rate of transplant recipients with a body mass index $\geq 35 \mathrm{~kg} / \mathrm{m}^{2}$ significantly increased from 7.8 to $11.0 \%$, the proportion of liver recipients with diabetes from 14.9 to $21.5 \%$, and the percentage of those with renal insufficiency from 21.6 to $29.8 \%$, which has taken patient care to a more complex level. The number of patients with hepatopulmonary syndrome, transplanted with MELD (Model for End-Stage Liver Disease) exception scores, increased from 54 in 2002 to 90 in 2008 in the USA. However, there has been a trend towards an improved 1-year graft survival during the same period of time. The identification of donor risk factors has aimed to indicate liver allograft quality for liver donors within the UNOS and Eurotransplant region $[20,21]$ with the goal to project failure-free survival following liver transplantation. A recent analysis has shown that above the donor risk index, recipient factors have to be taken into account to predict outcome after liver transplantation [22]. This combined model gives a significant prediction of outcome after orthotopic liver transplantation within the Eurotransplant region, 
Table 2. Cases and in-house deaths after liver transplantation (LT)

\begin{tabular}{lc}
\hline MMCs, $\mathrm{n}$ & 15 \\
Overall cases presented, $\mathrm{n}$ & 38 \\
Cases related to LT, $\mathrm{n}$ & 25 \\
Cases related to kidney transplantation, $\mathrm{n}$ & 11 \\
Other clinical cases transplant-related, $\mathrm{n}$ & 1 \\
Other clinical cases non-transplant-related, $\mathrm{n}$ & 1 \\
In-house deaths after LT, $\mathrm{n}$ & 23 \\
In-house deaths after LT presented at MMC, n & 19 \\
Age at death following LT, mean ( \pm standard deviation), & $53.9( \pm 9.4)$ \\
$\quad$ years & $7.5( \pm 6.1)$ \\
Time from death/incident until presentation at MMC, & \\
$\quad$ mean ( \pm standard deviation), weeks & 11.8 \\
Pediatric cases, \% & 88.2 \\
Adult cases, \% & \\
\hline
\end{tabular}

better than the Eurotransplant donor risk index alone. Identifying risk factors through preexisting parameters is a tool for predicting outcome and preventing avoidable harm. These factors, however, do not take risk factors within the transplantation center into account. MMCs again could function as an additional pathway for improving patient safety beyond donor and recipient (medical) risk factors. Aiming at the design of MMCs in liver transplantation, there are numerous factors to be taken into account. These factors are not restricted to the number and qualification of healthcare providers involved in a patient's treatment, but also include elements that are helpful to analyze medical incidents [9, 23]. Table 1 gives a list of elements including goals, structures, process categories, and expectations that help design MMCs. Even though human error is inevitable, 3 steps can be taken to measure and react to them: increasing the visibility of errors when they occur, having remedies at hand in order to rescue patients, and designing a work environment that reduces the frequency of human error [18].

\section{MMCs in Transplantation Surgery - a Single Center Review}

We summarized the cases presented at our center's MMCs in the years 2014 and 2015. We hold a monthly joint conference where all transplantation-related cases in our department are being presented, including kidney, pancreas, as well as liver transplantations. Not distinguishing between types of organs as the topic of transplantation MMCs remains a subject of debate and has rather traditional reasons at our institution. However, we do see overlapping reasons for discussion of cases among the teams, and oftentimes outcomes of a liver-related case serve as a learning tool for kidneyrelated cases as well. Especially the staff involved in patient treatment on the ward, infectious diseases, intensive care, and anesthesiology will treat all groups of patients regardless of their transplanted organ. Invitations to the MMCs are being sent to attendees about 3 weeks prior to the meeting, during which time case selection takes place. The meeting duration has been set to about 45-60 min.

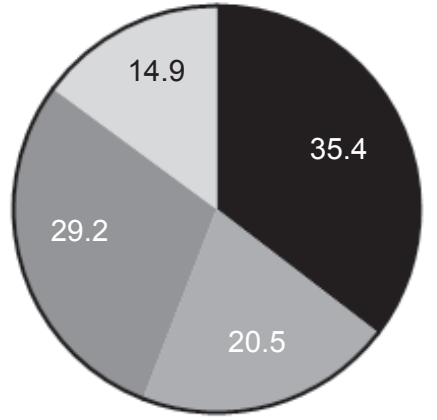

- Septic Shock/MOF $\square$ Cardiogenic Shock $\square$ PNF $\square$ Other

Fig. 1. Causes of death (\%) pertaining to cases of liver transplanted patients presented at our MMCs.

Within the past 2 years, 15 MMCs have taken place, in which 38 cases were discussed, out of which 25 were liver transplant-related. Out of these 25 liver transplant-related cases, 19 were in-house deaths (table 2). Reasons for in-house deaths were mainly multiorgan failure, septic shock, cardiogenic shock, as well as primary non-function (fig. 1). $64 \%$ of all cases were presented by a junior resident, $16 \%$ by an attending consultant, and $20 \%$ by a senior consultant. The sessions were chaired by the head of the Department for Transplantation Surgery. $88.2 \%$ of all cases discussed involved adult patients, $11.8 \%$ involved pediatric patients. An average of 7.5 weeks passed from the incident/death until the case was presented at an MMC. This long period was due to cases being collected for presentation at an interim meeting on patients who died due to infectious causes while in the intensive care unit (ICU). The main requirement for a case to be presented was death, with only a minor number of cases relating to other non-fatal incidents. Meeting minutes were written by a clinical assistant and distributed to the attendees of the meeting during the following days. The departments represented in these meetings involved Internal Medicine, Surgery, Immunology, Infectious Diseases, Intensive Care Medicine, and Anesthesiology.

\section{Learning from the Past, Preparing for the New - a Format for MMCs in Transplantation Surgery}

In order to improve the standard of care and the education of surgical trainees, MMCs need to be well planned and organized. There are no strict guidelines and regulations as to how they are to be conducted in liver transplant centers, and there are currently no guidelines or reports for MMCs held in liver transplant units published in the literature. Based on published models and our experience, we propose the following model as a helpful guide to organizing MMCs in liver transplant units $[9,23]$. The first question to ask is what attendees expect from a successful MMC, and above that how a conference can be planned in order to make it efficient. First, we defined 3 general points:

i) Input will be given from all staff involved in the incident.

ii) MMCs will be held following a structured framework to analyze factors that contributed to the incident. 


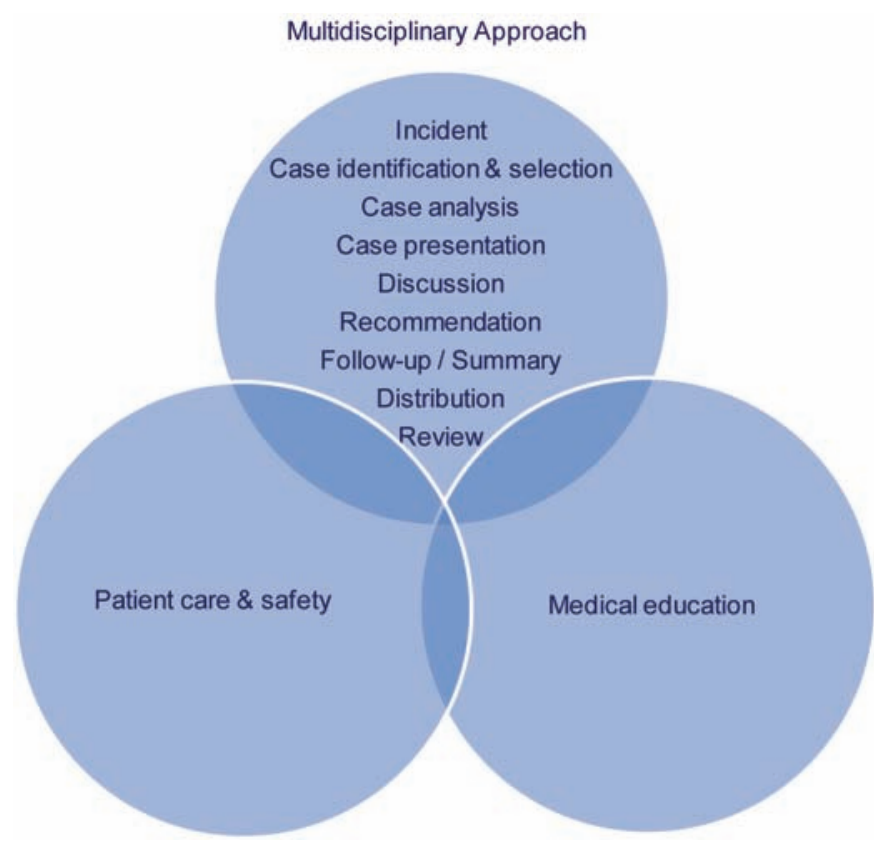

Fig. 2. Important subjects that need to be addressed in order to conduct MMCs.

iii) Reports will be written and distributed to the team members, assigning responsibility for follow-up recommendations and management to individuals.

Based on previously established guidelines $[9,24]$, the selection of points and questions triggers a number of helpful steps when designing MMCs (table 1).

The complexity of incidents involving liver transplanted patients requires MMCs to be held in a multidisciplinary fashion. The list of attendees should preferably include all types of healthcare providers and not be restricted to physicians alone. As a chairman and moderator, the chief of transplantation surgery and senior consultants can rotate and take turns. Besides hosting the meeting, the chairman will guide the discussion, and moderate to encourage input from all attendees and maintain constructive criticism. After all, the goal is to deter rather than expose deficiencies in treatment and management [9]. Meetings should be scheduled on a regular basis, and marked as a fixed date within the department's schedule. It is helpful to find a designated time in which most of the clinicians will be able to attend. Data on incidents can be collected by a member of the team or as a joint effort by several assigned members. The time between incident and presentation should be kept short, and recent incidents should be presented at the upcoming MMC when every attendee will be more likely to remember the case details. It remains a subject of debate as to what the limit of the number of cases presented should be. We recommend discussing all deaths, as well as severe adverse events that required surgical or medical intervention in order to prevent further harm (i.e., Dindo-Demartines-Clavien Grade III) [25]. Additionally, salient features of a surgical procedure (including such factors as equipment design and use, communication, team coordination, factors affecting individual performance, and work envi- ronment) and workflow management should be addressed by the team in order to find solutions. It will be helpful to revisit errors and group them statistically into types and frequency of occurrence at the end of each year in order to identify the most prevalent events (e.g., infections). Distributing the outcomes of each MMC to the entire team will update everyone and keep all members involved in newly addressed cases and the recommendations made. The primary goal of MMCs in liver transplantation will remain the improvement of patient care as well as the advancement of medical education. Figure 2 gives an example of structure components of MMCs.

\section{Discussion}

MMCs are powerful opportunities for learning, reflection, and improvement. However, methods of case identification, selection, presentation, and analysis vary among departments. Little has been published on framework structures that guide case investigation, and there is wide variation in how MMCs are conducted across departments and little conformity to known models for analyzing medical incidents. Best practice models for conduction of MMCs are urgently needed. Especially in the field of liver transplantation, patient care, safety, and medical education are characterized by an unmet complexity. Coordination of MMCs in liver transplantation takes time and energy. In general, the input of all involved is necessary to analyze the cases presented. A supportive environment of openness, honesty, as well as constructive criticism is the key prerequisite for the public sharing of medical errors, mishaps, and unexpected outcomes, together with comments on how the cases have affected staff members on a personal and professional level. The goal is to deter (not expose) either inappropriate management or unexpected negative outcomes, and gain insight into a system that may require fixing and attention. When a case is being presented and an analysis of the root cause has been performed, responsibilities for management and follow-up recommendations are to be shared among the involved healthcare providers in order to secure improved outcomes in the future. Even though the main requirement for a case to be presented at our department's MMCs is death, we strongly recommend discussing all cases of adverse events that required intervention to prevent further harm.

Throughout the different models described in the literature on conducting MMCs, core principles overlap. While one of these principles is to advance medical education and for senior professionals to function as role models, patient safety and quality of care are to be assured by the creation of better workflow arrangements and their establishment by the entire team. Procedures therefore need to be in place to ensure that suggested changes are carefully considered and implemented where appropriate.

While maintaining the traditional goals of MMCs, i.e. advancement of medical education and patient safety, we now move towards improved auditing and quality control in surgical practice. 


\section{Conclusion}

MMCs have the potential to combine both educational values and advancements in patient safety and quality of care. Even though reaching the highest standard of quality of care and education at surgical units is regarded as the main goal in academic medicine, little has been documented and analyzed with regard to MMC design, especially for a unique subgroup of patients where medical treatments are overlapping in many aspects. Here, we have listed guiding points on how to design and conduct these MMCs in an organized way while allowing for flexibility according to indi- vidual schedules. Especially in the field of transplantation surgery, improvements in patient safety in combination with the advancement of medical education need to be critically assessed. There is an urgent need for a structured approach to identifying system defects and establishing follow-up recommendations.

\section{Disclosure Statement}

No conflicts of interest reported.

\section{References}

1 Gordon LA: Gordon's Guide to the Surgical Morbidity and Mortality Conference. Philadelphia, PA, Handley and Belfus, 1994

2 Codman EA: A Study in Hospital Efficiency. Oakbrook Terrace, IL, JCAHO, 1996

3 ACGME: Program requirements for residency education in surgery; V B 1b1, editorial revisions, July 2004.

4 Institute of Medicine: To Err is Human: Building a Safer Health System. Washington, DC, National Academy Press, 2000

5 Institute of Medicine: Crossing the Quality Chasm: A New Health System for the 21st Century. Washington, DC, National Academy Press, 2001

6 Kohn L: To err is human: an interview with the Institute of Medicine's Linda Kohn. Jt Comm J Qual Improv 2000;26:227-234.

7 Vincent C: Understanding and responding to adverse events. N Engl J Med 2003;348:1051-1056.

8 Vincent C, Moorthy K, Sarker SK, Chang A, Darzi AW: Systems approaches to surgical quality and safety: from concept to measurement. Ann Surg 2004;239: 475-482.

9 Campbell WB: Surgical morbidity and mortality meetings. Ann R Coll Surg Engl 1988;70:363-365.

10 Hutter MM, Rowell KS, Devaney LA, Sokal SM, Warshaw AL, Abbott WM, Hodin RA: Identification of surgical complications and deaths: an assessment of the traditional surgical morbidity and mortality conference compared with the American College of Surgeons-National Surgical Quality Improvement Program. J Am Coll Surg 2006;203:618-624.

11 Murayama KM, Derossis AM, DaRosa DA, Sherman HB, Fryer JP: A critical evaluation of the morbidity and mortality conference. Am J Surg 2002;183:246-250.
2 Pierluissi E, Fischer MA, Campbell AR, Landefeld CS: Discussion of medical errors in morbidity and mortality conferences. Jama 2003;290:2838-2842.

13 Thomas EJ, Brennan T: Errors and adverse events in medicine: an overview; in Vincent CA (ed): Clinical Risk Management. Enhancing Patient Safety. London, BMJ Publications, 2001, pp. 31-44.

14 Vincent C, Neale G, Woloshynowych M: Adverse events in British hospitals: preliminary retrospective record review. BMJ 2001;322:517-519.

15 Gordon NL, Dawson AA, Bennett B, Innes G, Eremin O, Jones PF: Outcome in colorectal adenocarcinoma: two seven-year studies of a population. BMJ 1993;307: 707-710.

16 Birkmeyer JD, Siewers AE, Finlayson EV, Stukel TA, Lucas FL, Batista I, Welch HG, Wennberg DE: Hospital volume and surgical mortality in the United States. N Engl J Med 2002;346:1128-1137.

17 Begg CB, Riedel ER, Bach PB, Kattan MW, Schrag D, Warren JL, Scardino PT: Variations in morbidity after radical prostatectomy. N Engl J Med 2002;346:11381144.

18 Makary MA, Daniel M: Medical error - the third leading cause of death in the US. BMJ 2016;353:12139.

19 Thuluvath PJ, Guidinger MK, Fung JJ, Johnson LB, Rayhill SC, Pelletier SJ: Liver transplantation in the United States, 1999-2008. Am J Transplant 2010;10: 1003-1019.

20 Feng S, Goodrich NP, Bragg-Gresham JL, Dykstra DM, Punch JD, DebRoy MA, Greenstein SM, Merion RM: Characteristics associated with liver graft failure: the concept of a donor risk index. Am J Transplant 2006;6:783-790.
21 Braat AE, Blok JJ, Putter H, Adam R, Burroughs AK, Rahmel AO, Porte RJ, Rogiers X, Ringers J; European Liver and Intestine Transplant Association (ELITA) and Eurotransplant Liver Intestine Advisory Committee (ELIAC): The Eurotransplant donor risk index in liver transplantation: ET-DRI. Am J Transplant 2012; 12:2789-2796.

22 Blok JJ, Putter H, Rogiers X, van Hoek B, Samuel U, Ringers J, Braat AE; Eurotransplant Liver Intestine Advisory Committee: Combined effect of donor and recipient risk on outcome after liver transplantation: research of the Eurotransplant database. Liver Transpl 2015;21:1486-1493.

23 Aboumatar HJ, Blackledge CG Jr, Dickson C, Heitmiller E, Freischlag J, Pronovost PJ: A descriptive study of morbidity and mortality conferences and their conformity to medical incident analysis models: results of the morbidity and mortality conference improvement study, phase 1. Am J Med Qual 2007;22:232-238.

24 Mitchell EL, Lee DY, Arora S, Kenney-Moore P, Liem TK, Landry GJ, Moneta GL, Sevdalis N: Improving the quality of the surgical morbidity and mortality conference: a prospective intervention study. Acad Med 2013;88:824-830.

5 Dindo D, Demartines N, Clavien PA: Classification of surgical complications: a new proposal with evaluation in a cohort of 6,336 patients and results of a survey. Ann Surg 2004;240:205-213. 